\title{
ESPESSURA DAS SUBCAMADAS DA PAREDE CAROTÍDEA EM PACIENTES HIPERTENSOS
}

Rafael De Paolis Bonafé*, Luís F.R.S. Carvalho-Romano, Layde R. Paim; Edmilson R. Marques, Camila F. L. Vegian, José R. Matos-Souza, Roberto Schreiber, Wilson Nadruz Jr.

\section{Resumo}

A medida da espessura íntima-média (EIM) é o exame mais utilizado para estimar a aterosclerose subclínica na prática médica. Contudo, este exame não distingue um aumento da espessura da parede arterial causado por uma hipertrofia da camada média de outro aumento causado por doença aterosclerótica per se, a qual ocorre tipicamente na camada íntima. A hipertensão arterial é um relevante fator de risco cardiovascular, e pode, teoricamente, levar a aumentos tanto da camada média quanto da camada íntima vascular. Contudo, ainda não se sabe qual subcamada da EIM carotídea está mais hipertrofiada em hipertensos. O objetivo deste projeto foi aferir a espessura individual das subcamadas (íntima e média) de artérias carótidas em indivíduos hipertensos.

\section{Palavras-chave:}

Hipertensão, Cardiovascular, Ultrassom.

\section{Introdução}

A identificação de marcadores de risco e potenciais alvos terapêuticos para prevenção da doença cardiovascular representa uma prioridade no nosso país, onde mais de $30 \%$ das mortes se devem a doenças cardiovasculares. Neste sentido, é necessário desenvolver métodos complementares que estratifiquem o risco cardiovascular de forma mais precoce e acurada. A medida da espessura íntima-média (EIM) é o exame mais utilizado para estimar a aterosclerose subclínica na prática médica. Contudo, este exame não distingue um aumento da espessura da parede arterial causado por uma hipertrofia da camada média de outro aumento causado por doença aterosclerótica per se, a qual ocorre tipicamente na camada íntima. A hipertensão arterial é um relevante fator de risco cardiovascular, e pode, teoricamente, levar a aumentos tanto da camada média quanto da camada íntima vascular. Nosso grupo demonstrou recentemente ser capaz medir separadamente as subcamadas da carótida com ótima acurácia e reprodutibilidade. ${ }^{1}$
A

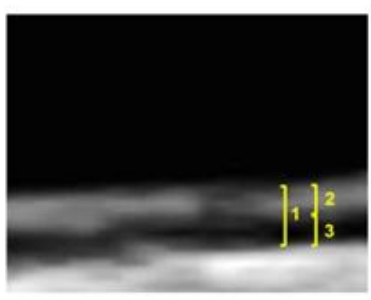

Transdutor $10 \mathrm{MHz}$
B

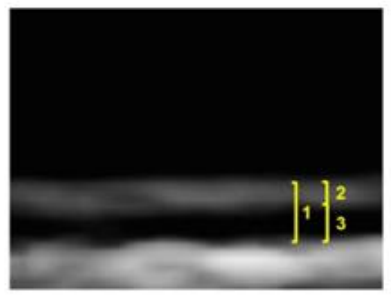

Transdutor $13 \mathrm{MHz}$
Figura 1. Método de US carotídeo bidimensional com transdutores vasculares de alta resolução, que permite separação das subcamadas íntima (2) e média (3) a partir da EIM (1).

O objetivo deste projeto é medir a espessura individual das subcamadas carótidas em pacientes hipertensos acompanhados no Hospital de Clínicas da UNICAMP.

\section{Resultados e Discussão}

Foram incluídos 70 indivíduos portadores de hipertensão arterial e coletadas informações referentes a idade, sexo, diabertes mellitus, índice de massa corpórea (IMC), pressão arterial (PA) e frequência cardíaca. Todos os pacientes foram submetidos a ultrassonografia carotídea de alta resolução em um aparelho GE Vivid Q da General Electrics. Os dados estão apresentados como média \pm desvio padrão ou como proporções.

Tabela 1. Características clínicas e ultrassonográficas dos pacientes estudados.

\begin{tabular}{|l|c|}
\hline Variável & $\mathbf{N}=\mathbf{7 0}$ \\
\hline Sexo, $\mathrm{n}(\%)$ & $32(47)$ \\
\hline Idade, anos & $60.2 \pm 10.7$ \\
\hline $\mathrm{IMC}, \mathrm{kg} / \mathrm{m}^{2}$ & $30.3 \pm 5.2$ \\
\hline PA sistólica, $\mathrm{mmHg}$ & $151.5 \pm 27.3$ \\
\hline PA diastólica, $\mathrm{mmHg}$ & $84.6 \pm 18.0$ \\
\hline Frequência cardíaca, bpm & $65.3 \pm 10.2$ \\
\hline Diabetes mellitus, $\mathrm{n}(\%)$ & $35(58)$ \\
\hline Espessura íntima, $\mathrm{mm}$ & $0.225 \pm 0.056$ \\
\hline Espessura média, $\mathrm{mm}$ & $0.564 \pm 0.111$ \\
\hline Espessura íntima-média, $\mathrm{mm}$ & $0.789 \pm 0.147$ \\
\hline
\end{tabular}

\section{Conclusões}

A espessura íntima média da parede carotídea é determinada principalmente pela camada média em pacientes hipertensos. Estes dados indicam que aumentos da EIM em hipertensos possam não ser derivados de aumentos da camada íntima, o qual é um marcador mais específico de aterosclerose. Estes resultados podem ser úteis na interpretação clínica de medidas de EIM obtidas em hipertensos na prática clínica.

PIBIC, FCM/Unicamp

\section{Agradecimentos}

1. Sardeli AV, Gáspari AF, Rossi G de, Souza GV de, Souza TMF de, Cavaglieri CR, et al. Carotid intima-media thickness is associated with media rather than intima thickness. Atherosclerosis. $1^{\circ}$ de junho de 2017;261:16971. 